\title{
Aortic root diameter is associated with HLA-B27: identifying the patient with ankylosing spondylitis at risk for aortic valve regurgitation
}

\author{
M. Baniaamam ${ }^{1,2} \mathbb{D}$. S. C. Heslinga ${ }^{3}$. T. C. Konings ${ }^{4}$ - M. L. Handoko ${ }^{4}$ O. Kamp ${ }^{4}$ - V. P. van Halm ${ }^{4}$. \\ I. E. van der Horst-Bruinsma ${ }^{3,5}$. M. T. Nurmohamed ${ }^{1,2,3}$
}

Received: 8 October 2021 / Accepted: 22 October 2021 / Published online: 2 November 2021

(c) The Author(s) 2021

\begin{abstract}
To assess the association between the aortic root diameter in HLA-B27 positive (+) and HLA-B27 negative (-) ankylosing spondylitis (AS) patients from the CARDAS cohort. The CARDAS study is a cross-sectional study in AS patients between 50 and 75 years who were recruited from a large rheumatology outpatient clinic. Patients underwent cardiovascular screening including echocardiography, with 2D, spectral, and color flow Doppler measurements. The aortic root was measured at sinuses of Valsalva during diastole. The aortic root diameter was adjusted for body surface area (BSA) (aortic root index, $\mathrm{cm} / \mathrm{m}^{2}$ ). 193 Consecutive AS patients were included of whom $158(82 \%)$ were HLA-B27 positive. The aortic root index was significantly higher in HLA-B27 + patients compared to HLA-B27- patients, respectively, $1.76 \mathrm{~cm} \pm 0.21 \mathrm{vs.} 1.64 \mathrm{~cm} \pm 0.14$, $p<0.001$. No difference was seen in the prevalence of aortic valve regurgitation (AVR), $p=0.8$. Regression analysis showed a significant association between HLA-B27 and aortic root index corrected for age, sex and cardiovascular risk factors ( $\beta$ $0.091,95 \%$ CI $0.015-0.168, p=0.02$ ). Especially, male HLA-B27 + patients had a significantly increased aortic root index compared to male HLA-B27- AS patients, respectively, $1.76 \mathrm{~cm}(1.63-1.88)$ and $1.59 \mathrm{~cm}(1.53-1.68), p<0.001$. We found an increased aortic root index in elderly HLA-B27+AS patients compared to HLA-B27- AS patients, especially in male patients. No difference was seen in the prevalence of AVR. However, as AVR can be progressive, echocardiographic monitoring in elderly male HLA-B27 + AS might be considered.
\end{abstract}

Keywords Ankylosing spondylitis · HLA-B27 genotype · Cardiovascular disease · Aortic root diameter · Transthoracic echocardiography

M. Baniaamam

m.baniaamam@reade.nl

1 Amsterdam Rheumatology and Immunology Center, Reade Rheumatology, Jan van Breemenstraat 2, 1056 AB Amsterdam, The Netherlands

2 Amsterdam Cardiovascular Sciences, Amsterdam, The Netherlands

3 Department of Rheumatology, Amsterdam UMC, Vrije Universiteit Amsterdam, Amsterdam, The Netherlands

4 Department of Cardiology, Amsterdam UMC, Vrije Universiteit Amsterdam, Amsterdam, The Netherlands

5 Amsterdam Rheumatology and Immunology Center, Amsterdam UMC, Vrije Universiteit Amsterdam, Amsterdam, The Netherlands

\section{Introduction}

Ankylosing spondylitis (AS) is an inflammatory joint disease associated with cardiac involvement. Aortic valve regurgitation (AVR) is a well-known cardiac complication described in AS patients [1,2]. Inflammation of the aortic root might weaken aortic wall strength with subsequent dilatation of the aortic root causing fibrotic thickening of the aortic cusps. In combination with shortening of the aortic cusps this might ultimately lead to AVR [3-5]. In the majority of patients with AVR, the disease course is chronic and slowly progressive and in severe cases can lead to congestive heart failure, arrhythmia and sudden death [6-8]. The American Heart Association/American College of Cardiology (AHA/ACC) and the European society of cardiology (ESC) state that AVR is pathological, regardless of its grade of severity $[8,9]$. Timely intervention with life 
style changes, pharmaceutical and/or surgical treatment of the aortic valve reduces the risk for severe complications [10]. Hence, follow-up is indicated in all cases of AVR [8, 9]. In this light, some advocate regular echocardiographic screening for AS patients [11]. However, the cost-benefit of echocardiographic screening in AS is currently unknown and to what extent AS specific (subclinical) cardiac pathology leads to clinically overt cardiovascular morbidity and mortality remains to be elucidated. Therefore, it is needed to identify a specific at risk AS population that might benefit from routine echocardiographic monitoring.

HLA-B27 genotype is associated with AS. Eighty to $90 \%$ of AS patients in the Western World, carry the HLA-B27 allele compared to a $5 \%$ prevalence in the general Western population [12]. Interestingly, the HLA-B27 genotype has also been associated with cardiac diseases including AVR in non-rheumatic patients $[4,5]$. The question rises whether the increased risk for cardiac diseases in AS patients is linked to the HLA-B27 genotype. Therefore, the presence of the HLA-B27 genotype may be a screening feature to identify AS patients at risk for AVR. Hence, we hypothesized that HLA-B27 positive (+) AS patients have a higher risk of developing AVR compared to HLA-B27 negative (-) AS patients, and, therefore, echocardiographic screening of HLA-B27 + AS patients could be of added value.

\section{Patients and methods}

\section{Study population}

Data of AS patients of the Cardiac disease in Ankylosing Spondylitis (CARDAS) cohort were used. The CARDAS cohort included AS patients aged between 50 and 75 years old who had a comprehensive cardiovascular screening. Subjects were consecutively recruited between March 2014 and September 2019 from the Rheumatology Department of Reade, Amsterdam, and the Netherlands. All patients fulfilled the 1984 Modified New York criteria for AS [13]. This study was conducted in accordance with the Helsinki Declaration and the approval was obtained from the ethics committee of the Slotervaart Hospital and Reade, Amsterdam, The Netherlands (NL44202.048.13). All participating patients gave written consent.

\section{Patient and disease characteristics}

All patients underwent a complete AS workup and cardiovascular screening including transthoracic echocardiographic (TTE) screening. Medical history was obtained by questionnaires and medical charts, including medication use, cardiovascular risk factors including smoking, hypertension, and dyslipidemia and history of cardiovascular disease. Hypertension was defined as present if a patient was treated with antihypertensive medication, had a systolic blood pressure $\geq 140 \mathrm{mmHg}$ or a diastolic blood pressure $\geq 90 \mathrm{mmHg}$ measured during physical examination. Furthermore, physical examination included height, weight, and blood pressure measurements. Body mass index (BMI) was calculated. Blood sample measurements included standard hematological assessment, C-reactive protein (CRP), and erythrocyte sedimentation rate (ESR). Disease activity was measured with the Bath Ankylosing Spondylitis Disease Activity Index (BASDAI), Bath Ankylosing Spondylitis Functional Index (BASFI), and the Ankylosing Spondylitis Disease Activity Score-CRP (ASDAS-CRP).

\section{Transthoracic echocardiography}

TTE was performed by experienced echo technicians at the Amsterdam UMC, location VUmc, a European Society of Cardiology certified echo-lab. To exclude inter-observer variability, all recordings of echocardiography data from both AS patients and controls were stored digitally and were afterwards analysed offline by a single cardiologist (T.C.K.). TTE was performed according to the protocol based on the guidelines provided by European Association of Echocardiography. Evaluation of cardiac function consisted of 2D, spectral and color flow Doppler recordings. 2D recordings were performed in parasternal long- and short-axis views, and apical four-, three-, and two-chamber views. The aortic root was measured at sinuses of Valsalva during diastole. The aortic root diameter was corrected for body surface area (BSA) according to the Dubois method (aortic root index) [14]. An aortic root index of $\geq 2.1 \mathrm{~cm} / \mathrm{m}^{2}$ was considered as aortic root dilatation $[15,16]$.

\section{Statistical analysis}

For data analysis SPSS Version 24.0 (IBM Corp., Armonk, New York) was used. Demographic and disease characteristics were summarized using descriptive statistics. Distribution of data was displayed by histograms. Values are expressed as mean \pm standard deviation (SD), median (interquartile range, IQR) or numbers (percentages, \%) where appropriate. Independent samples $t$ tests were used for comparisons of normally distributed continuous variables and the Mann-Whitney $U$ test for non-normally distributed variables. The Chi-squared test or Fisher's exact test $(n<10)$ was performed on dichotomous variables. Echocardiographic data were analysed using the unpaired samples $t$ test or the Mann-Whitney $U$ test, where appropriate. A level of $p<0.05$ was considered statistically significant. 


\section{Results}

\section{Patient characteristics}

In total, 193 consecutive AS patients were included of whom 158 were HLA-B27 + and 35 HLA-B27-. AS patients had, respectively, a mean age of $60( \pm 7)$ years and $61( \pm 7)$ years and $44(28 \%)$ and $11(31 \%)$ were female, respectively (Table 1). Both groups had a comparable disease duration (time since diagnosis), $36( \pm 11)$ and $30( \pm 14)$ years, and a moderate disease activity assessed with the ASDAS-CRP, $2.1( \pm 1.0)$ and $(2.3 \pm 1.0)$ (Table 1$)$. Furthermore, obesity and diabetes type II were more common in HLA-B27- AS patients, respectively, $18 \%$ vs $40 \%$ and $9 \%$ vs $20 \%$. History for cardiovascular disease was similar in both groups.

\section{Aortic root measurement and valvular disease}

The median aortic root index was significantly higher in HLA-B27 + patients compared to HLA-B27- patients: 1.76 $( \pm 0.21) \mathrm{cm} / \mathrm{m}^{2}$ vs $1.64( \pm 0.14) \mathrm{cm} / \mathrm{m}^{2}, p<0.001$. Furthermore, HLA-B27 + AS patients compared to HLA-B27- AS patients had more often aortic root dilatation $\left(\geq 2.1 \mathrm{~cm} / \mathrm{m}^{2}\right)$, $11(8 \%)$ and $1(3 \%), p=0.3$, respectively (Table 2$)$. The presence of aortic root dilatation in HLA-B27 + AS patients was seen significantly more often in patients with aortic valve regurgitation, $p=0.003$. The single case of aortic root dilatation in the HLA-B27- cohort had a mild AVR. Of the eleven cases of aortic root dilatation in HLA-B27 + AS patients four had no AVR, one had AVR, five had mild AVR, one severe AVR and in one AS patient had an aortic valve prosthesis. None of the AS patients had aortic valve stenosis and one AS patient had mitral valve stenosis.

\section{Association between HLA-B27 and aortic root index}

The results of the linear regression analysis (crude, adjusted and fully adjusted) are presented in Table 3 . The relation between HLA-B27 genotype and the aortic root index remained significant in the fully adjusted model corrected for age, sex and cardiovascular risk factors, B 0.091 (95\% CI $0.091-0.168), p=0.02$.

\section{Aortic root index, HLA-B27 genotype and sex}

The differences in aortic root index and sex and HLAB27 genotype are shown in Table 4. Male HLAB27 + patients had a significant increased aortic root index compared to male HLA-B27- AS patients, respectively, $1.76(1.63-1.88)$ and $1.59(1.53-1.68), p<0.001$. No difference was seen in female HLA-B27+and
Table 1 Baseline characteristics

\begin{tabular}{|c|c|c|}
\hline Patient characteristics & HLA-B27 + & HLA-B27 - \\
\hline$n$ & 158 & 35 \\
\hline Age, years & $60 \pm 7$ & $61 \pm 7$ \\
\hline Sex, female & $44(28)$ & $11(31)$ \\
\hline $\mathrm{BSA}, \mathrm{m}^{2}$ & $1.91 \pm 0.19$ & $2.00 \pm 0.20$ \\
\hline BMI, $\mathrm{m}^{2} / \mathrm{kg}$ & $26.2 \pm 4.1$ & $28.7 \pm 3.9$ \\
\hline Systolic blood pressure, $\mathrm{mmHg}$ & $133 \pm 16$ & $136 \pm 15$ \\
\hline Diastolic blood pressure, $\mathrm{mmHg}$ & $83 \pm 7$ & $86 \pm 8$ \\
\hline \multicolumn{3}{|l|}{ Disease activity and severity } \\
\hline Disease duration, years & $36 \pm 11$ & $30 \pm 14$ \\
\hline $\mathrm{ESR}, \mathrm{mm} / \mathrm{h}$ & $7(4-14)$ & $9(5-17)$ \\
\hline $\mathrm{CRP}, \mathrm{mg} / \mathrm{L}$ & $2.7(1.2-7.6)$ & $3.3(1.1-8.1)$ \\
\hline ASDAS-CRP & $2.1 \pm 1.0$ & $2.3 \pm 1.0$ \\
\hline BASDAI & $3.3 \pm 2.2$ & $4.0 \pm 2.4$ \\
\hline BASFI & $3.6 \pm 2.4$ & $4.0 \pm 2.6$ \\
\hline \multicolumn{3}{|l|}{ Cardiovascular risk factors } \\
\hline \multicolumn{3}{|l|}{ Smoking } \\
\hline Current & $33(21)$ & $6(17)$ \\
\hline Ever & $111(70)$ & $23(66)$ \\
\hline Pack years, years & $26.2 \pm 14.0$ & $26.4 \pm 16.8$ \\
\hline \multicolumn{3}{|l|}{ Hypertension } \\
\hline Criteria & $93(59)$ & $25(71)$ \\
\hline Patient history & $59(37)$ & $17(49)$ \\
\hline Obesity & $28(18)$ & $14(40)$ \\
\hline Hypercholesterolemia & $28(18)$ & $8(23)$ \\
\hline Diabetes type II & $15(9)$ & $7(20)$ \\
\hline \multicolumn{3}{|l|}{ History of cardiovascular disease } \\
\hline Angina pectoris & $2(1)$ & $3(9)$ \\
\hline Myocardial infarction & $10(6)$ & $2(6)$ \\
\hline Stroke & $5(3)$ & $2(6)$ \\
\hline TIA & $3(2)$ & $1(3)$ \\
\hline CVA & $2(1)$ & $1(3)$ \\
\hline Peripheral ischemia & $1(1)$ & $0(0)$ \\
\hline CABG & $6(4)$ & $2(6)$ \\
\hline \multicolumn{3}{|l|}{ Family history (first degree) } \\
\hline AP/MI & $19(12)$ & $5(14)$ \\
\hline CVA/TIA & $11(7)$ & $3(9)$ \\
\hline \multicolumn{3}{|l|}{ Medication } \\
\hline Lipid modifying drug & $29(18)$ & $9(26)$ \\
\hline Antihypertensives & $68(43)$ & $17(49)$ \\
\hline Biologic DMARDs (anti-TNF) & $58(37)$ & $12(34)$ \\
\hline
\end{tabular}

Values are displayed as mean \pm standard deviation (SD), median (IQR) or frequencies with corresponding percentages (\%)

$B S A$ body surface area, $B M I$ body mass index, ESR erythrocyte sedimentation rate, $C R P$ C-reactive protein, $A S D A S$ ankylosing spondylitis disease activity score, $B A S D A I$ bath ankylosing spondylitis disease activity score, $B A S F I$ bath ankylosing spondylitis functional index, $T I A$ transient ischemic attack, $C V A$ cerebral vascular accident, $C A B G$ coronary artery bypass graft, $A P$ angina pectoris, $M I$ myocardial infarction

*Significance level of $p \leq 0.05$ 
Table 2. Echocardiographic parameters

\begin{tabular}{llll}
\hline Echocardiography & HLA-B27 + & HLA-B27 - & $p$ value \\
\hline Aortic root, cm $($ mean $\pm \mathrm{SD})$ & $3.35 \pm 0.43$ & $3.25 \pm 0.28$ & 0.12 \\
Aortic root index, $\mathrm{cm} / \mathrm{m}^{2}(\mathrm{mean} \pm \mathrm{SD})$ & $1.76 \pm 0.21$ & $1.64 \pm 0.14$ & $<0.001^{*}$ \\
Aortic root dilatation $\left(\geq 2.1 \mathrm{~cm} / \mathrm{m}^{2}\right)(n, \%)$ & $11(8)$ & $1(3)$ & 0.5 \\
Aortic valve regurgitation $(n, \%)$ & $34(22)$ & $8(24)$ & 0.8 \\
Trace $(n, \%)$ & $13(8)$ & $3(9)$ & \\
Mild $(n, \%)$ & $18(12)$ & $5(15)$ & \\
Moderate $(n, \%)$ & $4(3)$ & 0 & 0.25 \\
Severe $(n, \%)$ & $1(1)$ & 0 & \\
Prothesis $(n, \%)$ & $1(1)$ & 0 & $17(49)$ \\
Mitral valve regurgitation $(n, \%)$ & $52(34)$ & $16(46)$ & \\
Mild $(n, \%)$ & $49(32)$ & $1(3)$ & \\
Moderate $(n, \%)$ & $3(2)$ & $0(0)$ & \\
Severe $(n, \%)$ & $0(0)$ & $0(0)$ & \\
Prothesis $(n, \%)$ & $0(0)$ &
\end{tabular}

Values are displayed as mean \pm standard deviation $(\mathrm{SD})$ or frequencies with corresponding percentages (\%). No cases of aortic valve stenosis and only one case of mitral valve stenosis were assessed

*Significance level of $p \leq 0.05$

Table 3 Association of HLA-B27 genotype with the aortic root index

\begin{tabular}{|c|c|c|c|c|c|c|}
\hline & \multicolumn{2}{|l|}{ Crude model } & \multicolumn{2}{|l|}{ Adjusted model $^{\mathrm{a}}$} & \multicolumn{2}{|l|}{ Fully adjusted model ${ }^{\mathrm{b}}$} \\
\hline & Beta & $p$ value & Beta & $p$ value & Beta & $p$ value \\
\hline Aortic root index, $\mathrm{cm} / \mathrm{m}^{2}$ & $0.121(0.045-0.198)$ & $0.002 *$ & $0.123(0.048-0.199)$ & $0.002 *$ & $0.091(0.015-0.168)$ & $0.02 *$ \\
\hline
\end{tabular}

Values are displayed as odds ratio with corresponding $95 \%$ confidence interval

*Significance level of $p \leq 0.05$

${ }^{\mathrm{a}}$ Adjusted for age and gender

${ }^{\mathrm{b}}$ Adjusted for age, gender, systolic blood pressure, diastolic blood pressure, hypercholesterolemia, BMI, Diabetes Mellitus type 2 and family history of cardiovascular diseases

Table 4 Gender differences in aortic root index, aortic root dilatation, and aortic valve regurgitation

\begin{tabular}{|c|c|c|c|c|c|c|}
\hline & \multicolumn{2}{|l|}{ Male } & \multirow[t]{2}{*}{$p$ value } & \multicolumn{2}{|l|}{ Female } & \multirow[t]{2}{*}{$p$ value } \\
\hline & HLA-B27 + & HLA-B27 - & & HLA-B27 + & HLA-B27 - & \\
\hline$n=$ & 114 & 24 & & 44 & 11 & \\
\hline Aortic root index, $\mathrm{cm} / \mathrm{m}^{2}$ & $1.76(1.63-1.88)$ & $1.59(1.53-1.68)$ & $<0.001 *$ & $1.66(1.53-1.92)$ & $1.64(1.54-1.83)$ & 0.91 \\
\hline Aortic root dilatation, $n(\%)$ & $7(7)$ & 0 & 0.35 & $4(11)$ & $1(10)$ & 1.00 \\
\hline Aortic valve regurgitation, $n(\%)$ & $23(20)$ & $5(23)$ & 0.80 & $11(26)$ & $3(27)$ & 0.94 \\
\hline
\end{tabular}

Values are displayed as median (IQR) or frequencies with corresponding percentages (\%). No cases of aortic valve stenosis and only one case of mitral valve stenosis

*Significance level of $p \leq 0.05$

HLA-B27- AS patients, respectively, 1.66 (1.53-1.92) and $1.64(1.54-1.83), p=0.91$. Furthermore, male HLAB27 + AS patients also had an increased aortic root index compared to female HLA-B27 + AS patients.

\section{Discussion}

In the present study, the association between HLA-B27 genotype and aortic root diameter in AS patients was 
investigated. HLA-B27 + AS patients had a significantly increased aortic root index compared to HLA-B27- AS patients. This association was not explained by difference in age, sex nor cardiovascular risk factors. The prevalence of AVR was, however, similar in both groups. Furthermore, aortic dilatation was seen more often in HLAB27 + AS patients, albeit this reached no statistical significance. Finally, our data suggest a sex and HLA-B27 genotype linked difference in aortic root index as male HLA-B27 + patients had an increased aortic root index compared to the HLA-B27- male patients and the overall female AS patients.

The HLA-B27 antigen is assumed to misfold causing an unfolded protein response (UPR). This might result in IL-23 upregulation by macrophages and lamina propria mononuclear cells and leading to activation of the IL-23/ IL-17 inflammatory pathway, increasing susceptibility to AS [17-19]. Pathology studies have shown that IL23-Dependent $\gamma / \delta$ T-cells (IL23 + T-cell) are specifically expressed in entheseal organs such as entheses (the primary inflammatory target in AS), ciliary body of the eye, and aortic root and aortic valves $[17,20]$. Entheseal organs are avascular in their fibrocartilaginous regions, however, microdamages of entheseal tissue due to continuous exposure to mechanical forces are common and appear to be associated with tissue repair responses and vessel ingrowth $[21,22]$. It is assumed that enthesis-resident IL23 + T-cells have a homeostatic role in entheseal tissue repair. However, enthesis-resident IL23 + T-cells can also trigger a pro-inflammatory cascade as IL-23 binding induces IL-17 and IL-22 production leading to inflammation, bone loss, and ossification [17, 23]. Therefore, IL-23 upregulation possibly also results in activation of in situ IL23 + T-cells in aortic root and valves leading to local inflammation with subsequently inflammation of the aortic root and valves. In fact, murine studies have shown inflammation of entheses and aortic root and valves after infusion with IL-23 [20].

Our study partially confirms our hypothesis as HLAB27 + AS patients did not have an increased prevalence of aortic valve disease as was expected. However, HLAB27 + AS patients did have an increased aortic root index and had more often aortic root dilatation. To our knowledge, this finding has not been reported before. Our results may be indicative for the preclinical state of aortic valve disease in HLA-B27 + AS patients. At an older age HLA-B27 + AS patients may have a higher risk at developing aortic valve disease as inflammation of the aortic root and valves is progressive of nature [7]. Klingberg et al. found also no relation between HLA-B27 genotype and aortic valve regurgitation [11]. However, in this study assessment of this relation was not the primary objective and the AS subjects were 10 years younger. Moreover, Huppert et al. found, in HLA-B27 + juvenile arthritis patients, a higher prevalence of aortic valve regurgitation compared to HLA-B27- non-rheumatic controls, respectively, $10 \%(4 / 40)$ vs $0 \%(0 / 40)$ [24]. However, this study was performed in children $<18$ years of age and the control group consisted of non-rheumatic HLA-B27- subjects.

Our data suggest a sex and HLA-B27 genotype linked difference in aortic root index in disadvantage for male HLAB27 + patients. In this light, the findings of Bergfeldt et al. are important as they showed that patients needing a pacemaker due to severe conduction disturbances were primarily male HLA-B27 + patients [25].

Our study did have some limitations. First, due to the cross-sectional study design, the associations found in this study are not necessarily causal. Therefore, the (potential) long-term consequences of the cardiac manifestations we observed in our patients still need to be demonstrated. AS is predominant in male AS patients, therefore, the female subgroup was relatively small what could have masked differences between HLA-B27 + and HLA-B27 women.

In conclusion, our study demonstrated an increased aortic root index in elderly HLA-B27 + AS patients, especially in male patients. This did not already translated in an increased prevalence of aortic valve regurgitation in this subgroup. However, this finding is important as inflammation of the aortic root and valve in chronic inflammatory disease are progressive and may evolve in severe complications. Therefore, to recognize the AS patients at risk for this cardiac disease, echocardiographic monitoring, particularly in elderly male HLA-B27 + AS subjects should be considered. Obviously, prospective studies should determine the long-term outcomes as well the cost effectiveness of echocardiographic screening in this subgroup.

Acknowledgements The authors are grateful to all study participants, as well as all rheumatology nurses involved in patients management, and to Vidya Lall-Enait for the planning and management of all cardiac echoes at the Amsterdam UMC, location Vrije Universiteit Amsterdam. The data have been presented previously as abstract at the ACR Convergence 2020 [26].

Author contributions MB partly recruited and included participants, analysed and interpreted the patient data and was a major contributor in writing the manuscript. $\mathrm{SCH}$ partly recruited and included participants, substantially contributed to the conception and design of the work and was a major contributor in writing the manuscript. MTN substantially contributed to the conception and design of the work, made a major contribution in developing the study protocol and reviewing the manuscript for important intellectual content and acted as leader of the study project. VPH, MLH, IEHB and OK had a major contribution in interpreting the patient data and they had a major contribution in reviewing the manuscript for important intellectual content. TCK analysed all echocardiographic results and had a major contribution in reviewing the manuscript for important intellectual content. All authors read and approved the final manuscript.

Funding This research was partially funded by ReumaNederland. 


\section{Declarations}

Conflict of interest All authors have nothing to disclose

Ethical approval information This study was approved by the Ethics committee of the Slotervaart Hospital/Reade (NL44202.048.13) and written informed consent was obtained from all patients prior to inclusion.

Data sharing statement The datasets generated during and/or analysed during the current study are available from the corresponding author on reasonable request.

Open Access This article is licensed under a Creative Commons Attribution 4.0 International License, which permits use, sharing, adaptation, distribution and reproduction in any medium or format, as long as you give appropriate credit to the original author(s) and the source, provide a link to the Creative Commons licence, and indicate if changes were made. The images or other third party material in this article are included in the article's Creative Commons licence, unless indicated otherwise in a credit line to the material. If material is not included in the article's Creative Commons licence and your intended use is not permitted by statutory regulation or exceeds the permitted use, you will need to obtain permission directly from the copyright holder. To view a copy of this licence, visit http://creativecommons.org/licenses/by/4.0/.

\section{References}

1. Roldan CA, Chavez J, Wiest PW, Qualls CR, Crawford MH (1998) Aortic root disease and valve disease associated with ankylosing spondylitis. J Am Coll Cardiol 32(5):1397-1404

2. Palazzi C, D’Angelo S, Lubrano E, Olivieri I (2008) Aortic involvement in ankylosing spondylitis. Clin Exp Rheumatol 26(349):131-134

3. Bulkley BH, Roberts WC (1973) Ankylosing spondylitis and aortic regurgitation. Description of the characteristic cardiovascular lesion from study of eight necropsy patients. Circulation 48(5):1014-1027

4. Bergfeldt L, Insulander P, Lindblom D, Moller E, Edhag O (1988) HLA-B27: an important genetic risk factor for lone aortic regurgitation and severe conduction system abnormalities. Am J Med 85(1):12-18

5. Bergfeldt L (1997) HLA-B27-associated cardiac disease. Ann Intern Med 127(8 Pt 1):621-629

6. Rigolin VH, Bonow RO (2006) Hemodynamic characteristics and progression to heart failure in regurgitant lesions. Heart Fail Clin 2(4):453-460

7. Flint N, Wunderlich NC, Shmueli H, Ben-Zekry S, Siegel RJ, Beigel R (2019) Aortic regurgitation. Curr Cardiol Rep 21(7):65

8. Nishimura RA, Otto CM, Bonow RO, Carabello BA, Erwin JP 3rd, Guyton RA et al (2014) 2014 AHA/ACC Guideline for the Management of Patients With Valvular Heart Disease: a report of the American College of Cardiology/American Heart Association Task Force on Practice Guidelines. Circulation 129(23):e521-643

9. Vahanian A, Alfieri O, Andreotti F, Antunes MJ, Baron-Esquivias $\mathrm{G}$, Baumgartner $\mathrm{H}$ et al (2012) Guidelines on the management of valvular heart disease (version 2012): the Joint Task Force on the Management of Valvular Heart Disease of the European Society of Cardiology (ESC) and the European Association for CardioThoracic Surgery (EACTS). Eur J Cardiothorac Surg 42(4):S1-44

10. Baumgartner H, Falk V, Bax JJ, De Bonis M, Hamm C, Holm PJ et al (2017) 2017 ESC/EACTS Guidelines for the management of valvular heart disease. Eur Heart J 38(36):2739-2791
11. Klingberg E, Svealv BG, Tang MS, Bech-Hanssen O, Forsbladd'Elia H, Bergfeldt L. Aortic Regurgitation Is Common in Ankylosing Spondylitis: Time for Routine Echocardiography Evaluation? Am J Med. 2015;128(11):1244-50 e1.

12. Reveille JD (1998) HLA-B27 and the seronegative spondyloarthropathies. Am J Med Sci 316(4):239-249

13. van der Linden S, Valkenburg HA, Cats A (1984) Evaluation of diagnostic criteria for ankylosing spondylitis. A proposal for modification of the New York criteria. Arthritis Rheum 27(4):361-368

14. Du Bois D, Du Bois EF (1989) A formula to estimate the approximate surface area if height and weight be known. 1916. Nutrition 5(5):303-311 (discussion 12-3)

15. Saura D, Dulgheru R, Caballero L, Bernard A, Kou S, Gonjilashvili N et al (2017) Two-dimensional transthoracic echocardiographic normal reference ranges for proximal aorta dimensions: results from the EACVI NORRE study. Eur Heart J Cardiovasc Imaging 18(2):167-179

16. Evangelista A, Flachskampf FA, Erbel R, Antonini-Canterin F, Vlachopoulos C, Rocchi G et al (2010) Echocardiography in aortic diseases: EAE recommendations for clinical practice. Eur J Echocardiogr 11(8):645-658

17. Reinhardt A, Yevsa T, Worbs T, Lienenklaus S, Sandrock I, Oberdorfer L et al (2016) Interleukin-23-Dependent gamma/delta T Cells Produce Interleukin-17 and Accumulate in the Enthesis, Aortic Valve, and Ciliary Body in Mice. Arthritis Rheumatol 68(10):2476-2486

18. DeLay ML, Turner MJ, Klenk EI, Smith JA, Sowders DP, Colbert RA (2009) HLA-B27 misfolding and the unfolded protein response augment interleukin-23 production and are associated with Th17 activation in transgenic rats. Arthritis Rheum 60(9):2633-2643

19. Colbert RA, Navid F, Gill T (2017) The role of HLA-B*27 in spondyloarthritis. Best Pract Res Clin Rheumatol 31(6):797-815

20. Sherlock JP, Joyce-Shaikh B, Turner SP, Chao CC, Sathe M, Grein $\mathrm{J}$ et al (2012) IL-23 induces spondyloarthropathy by acting on ROR-gammat+ CD3+CD4-CD8-entheseal resident T cells. Nat Med 18(7):1069-1076

21. Benjamin M, McGonagle D (2009) The enthesis organ concept and its relevance to the spondyloarthropathies. Adv Exp Med Biol 649:57-70

22. Bridgewood C, Sharif K, Sherlock J, Watad A, McGonagle D (2020) Interleukin-23 pathway at the enthesis: the emerging story of enthesitis in spondyloarthropathy. Immunol Rev 294(1):27-47

23. Gravallese EM, Schett G (2018) Effects of the IL-23-IL-17 pathway on bone in spondyloarthritis. Nat Rev Rheumatol 14(11):631-640

24. Huppertz H, Voigt I, Muller-Scholden J, Sandhage K (2000) Cardiac manifestations in patients with HLA B27-associated juvenile arthritis. Pediatr Cardiol 21(2):141-147

25. Bergfeldt L, Moller E (1986) Pacemaker treated women with heart block have no increase in the frequency of HLA-B27 and associated rheumatic disorders in contrast to men-a sex linked difference in disease susceptibility. J Rheumatol 13(5):941-943

26. Baniaamam M HS, Handoko M, Konings T, Kamp O, van Halm V, van Denderen J, van der Horst-Bruinsma I, Nurmohamed M. . Identifying the as Patient at Risk: Is Aortic Root Diameter Associated with HLA-B27? [abstract]. Arthritis Rheumatol 2020;72 (suppl 10).

Publisher's Note Springer Nature remains neutral with regard to jurisdictional claims in published maps and institutional affiliations. 